\title{
J
}

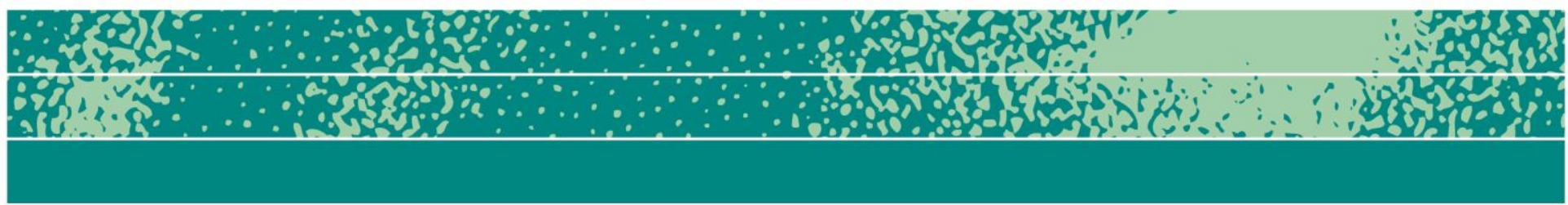

\section{O Organization, Where Art Thou? Tracing the Multiple Layers of Ambiguous and Shifting Boundary Processes in a Formal Organization}

\author{
Marte Fanneløb Giskeødegård
}

\begin{abstract}
In this article, I use an empirical case from a Norwegian transnational maritime company to discuss organizational boundaries and, implicitly, organizational form. I focus on the relationship of the formal organization as a legal entity to its outside world and ask how boundary work toward external actors takes form. My empirical case shows that there is not an unproblematic "inside" that engages with the outside world and, as a result, I question the usefulness of some of the concepts used to talk about boundary processes. To understand the latter, where the boundaries drawn are multiple, flexible, and dependent on the situation, I adopt Bowker and Star's (2000) concept of "boundary object," which allows the discussion to focus on boundaries in terms of the continuous work of making a "shared space", rather than of limits between the various parties.
\end{abstract}

\section{Keywords}

Organizational anthropology, organizational form, organizational boundaries, boundary object, organizational theory, Norway
Page 1 of 21

JBA 5(1): 116-136

Autumn 2016

(C) The Author(s) 2016 ISSN 2245-4217

www.cbs.dk/jba 


\section{Introduction}

The geographer Peter Dicken (2011: 110) defined a transnational company as a firm with "the power to coordinate and control operations in more than one country, even if it does not own them."1 Moreover, he described transnational companies as "networks within networks," owing to both the companies' internal structure and their complex bonds with the outside world. This description is a helpful point of departure for the current topic as it raises timely questions concerning what arenas are most relevant when defining what makes up "the organization."

In this article, I use an empirical case from a Norwegian transnational maritime company to discuss organizational boundaries. I focus on the relationship of the formal organization as a legal entity to its outside world and ask how boundary work toward external actors takes form. Here I want to raise the question of whether this "inside" world is easily identifiable. I thus explore the question of how to identify a formal organization by problematizing what criteria define actors as "inside" and "outside," as well as the significance of situations where boundaries between actors are emphasized. A great deal can be learned about social and organizational dynamics by examining boundary processes (Paulsen and Hernes 2003). My aim is to show the continuous processes involved in creating a formal organization. I also stress how these processes involve multiple layers of ambiguous and shifting organizational boundaries that are actualized simultaneously, and how it is possible to draw boundaries at different places, depending on the position taken and the boundary marker chosen. As such, my empirical case should have both theoretical and methodological implications for anthropologists studying formal organizations.

\section{Empirical case}

The Norwegian transnational maritime company under examination in this study, Supply Inc., ${ }^{2}$ provides the merchant fleet with products and services. Its customers are primarily ship owners who own multiple vessels and manage these vessels' various needs as they travel from port to port around the world. Supply Inc. promises to make this management process easier by offering them reliable, high-quality products and services worldwide. Key to the company's sales offer is a globally distributed delivery network, combined with a locally sensitive customer

\footnotetext{
1 The empirical data is from my PhD project conducted at the department of social anthropology at NTNU. I want to thank the committee members, Ann Jordan and Jakob Krause-Jensen, for their critique of my dissertation, which inspired this article. I also want to thank the anonymous reviewers for providing constructive criticism that helped me develop it further, Finally, I want to thank Møreforsking for providing funds that contributed to the possibility of my writing this article.

${ }^{2}$ Fictitious name.
} 
service structure that includes customer service centres. The ship owners always call their local customer service centre-regardless of where in the world they need the company's services. It is then up to Supply Inc. to make the arrangements internally, so that the vessel in need of products receives them at whatever port in the world it happens to be located at that given moment. Supply Inc. consequently needs to be represented both in the country of origin of the customers and in the ports frequented by the vessels. As a result, Supply Inc. has a market-oriented drive for transnational expansion (Dicken 2011). To meet the needs of these customers, Supply Inc. offers its services in over 120 countries around the world, with multiple ports in many of these countries. To achieve such a far-reaching presence, Supply Inc. must rely on hired external agents to deliver its products on its behalf in ports where it is not financially sound to set up its own branch. Hence, for Supply Inc. to uphold the promise it makes to its customers concerning the vast reach of its delivery structure, these external agents are an essential part of its business network.

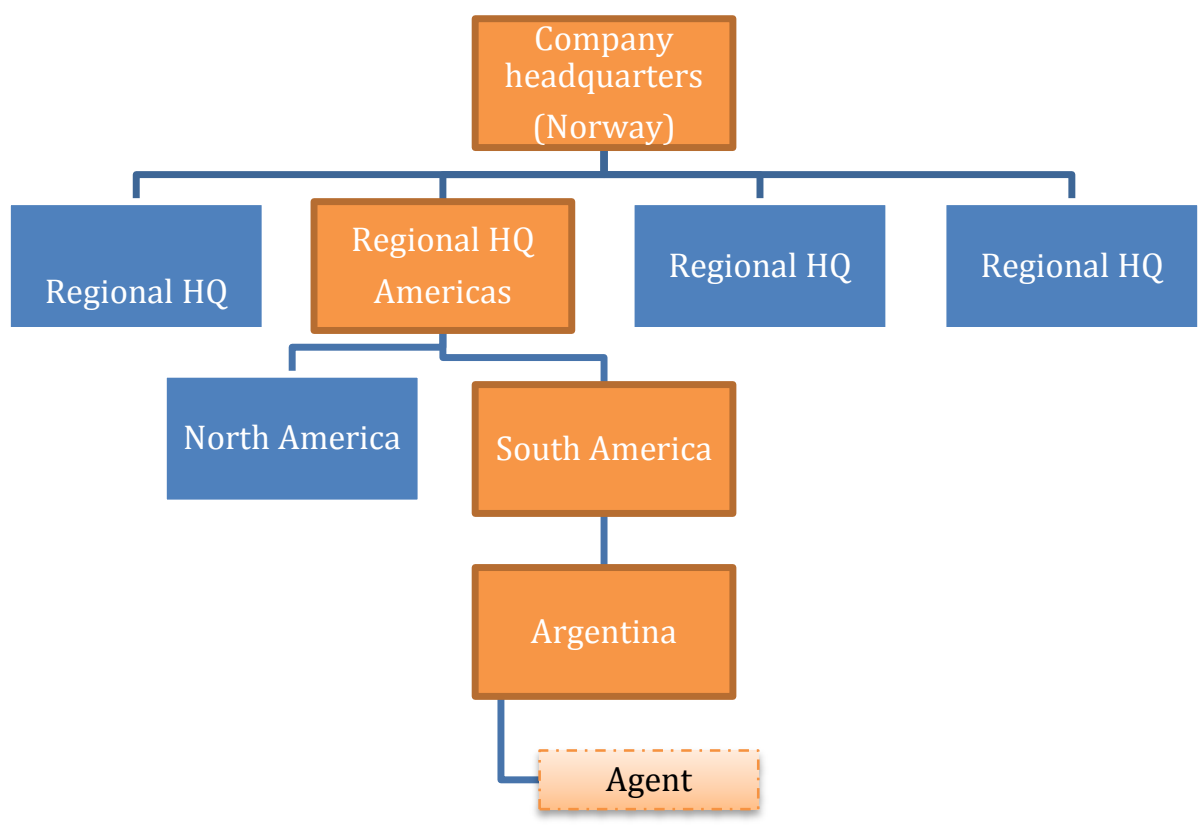

Figure 1: Organizational chart illustrating the administrative chain of command in Supply Inc.

These agents are administered by the nearest proper Supply Inc. branch office. As is evident in the organizational chart displayed below in Figure 1, the company has administratively divided the world into regions, but all sections ultimately answer back to the headquarters in Norway. Within this company, I have conducted fieldwork at its headquarters in Norway, at a regional headquarters for the Americas located in the United States, and at a branch office in Argentina. ${ }^{3}$ If this

${ }^{3}$ In total, I have spent about sixteen months of participant observation in these offices in two different projects, divided between six months in 2005 and the rest in 2008/09, and I have supplemented these data with individual semi-structured interviews both during these periods of time and in the following years. 
region is taken as an example, all of the branches in America answer to the regional headquarters in Texas, but the Americas have been further divided into North (Texas) and South (Brazil). This means that Argentina most often answered to Brazil, and that Brazil then reported back to Texas. The Supply Inc. office in Argentina, for its part, administered the company's relationship to four hired external agents spread across the country.

Another significant factor concerning the topic at hand is that Supply Inc. is part of a wider conglomerate, where the company makes up one part of a larger group of companies that are involved in the maritime industry in various ways. The conglomerate consists of several different companies, with the largest one having over 4500 employees. Because the various companies are involved in different kinds of activities (in addition to the maritime industry), the conglomerate has grouped companies into business sectors based on industry affiliation, resulting in three levels of organizational hierarchy at the headquarters.

The conglomerate therefore had some elements common to the entire group, but each company within the group is its own legal entity with its own business profile. According to the senior Vice President of $\mathrm{HR}$, the members of central management in the conglomerate see themselves as global policymakers, whereas the respective companies carry out the delivery of these policies locally. As a case in point, corporate values are common to the entire conglomerate. In the event that the conglomerate does not have a policy on a certain topic, the actors are free to create their own policy as long as it complies with the conglomerate's philosophy and policy framework.

As illustrated in Figure 2, the line between the conglomerate and Supply Inc. seems well defined, and there exist clear lines of communication. However, the relationships within the conglomerate are far more intertwined than the organizational hierarchy suggested in Figure 2. While the conglomerate as a whole has thousands of employees, only eighty individuals work directly in its headquarters. The vast number of employees are therefore found in the respective companies. The lower levels of the hierarchical structure are part of the "team" on the level of organizational hierarchy above them. For example, the central management team for the maritime business sector includes all company presidents for the companies that make up this particular sector. This complicates the idea of the conglomerate fulfilling the role of global policymaker. Staff and business activities are primarily conducted by the respective companies, and the companies therefore must have a say in how the policies for the group are outlined. 


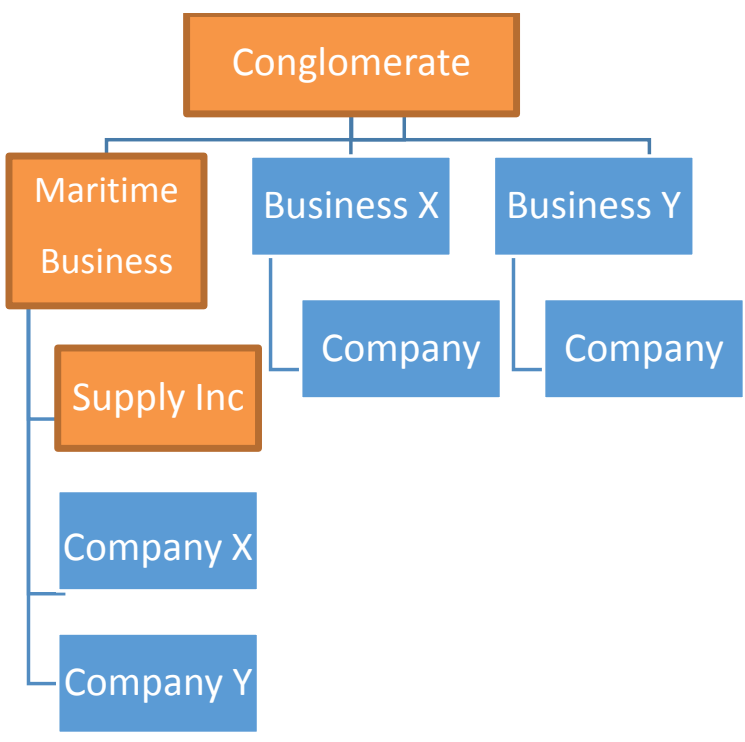

Figure 2: Organizational chart illustrating how the conglomerate organizes its activities

This brings the discussion back to the focus on organizational boundaries. To understand organizational life one needs to address the complexity of organizational form head on-in particular, how boundaries are conceptualized, constructed, and negotiated through organizational activity (e.g., Paulsen and Hernes 2003, Dahles and Leng 2005, Nardi 2007, Scott and Davis 2007). The globally distributed organization of Supply Inc., its dependence on external agents, as well as its membership of a wider conglomerate, position it as a good empirical case for learning more about organizational boundary processes. How can employees have a clear sense of Supply Inc. as an entity in its own rightseparate from the Conglomerate and the hired agents-while such actors at the same are an essential part of what Supply Inc. offers its customers and/or participate in the making of some of the company's policies and guidelines? Based on Auge's work, Garsten and Nyquist (2013: 12) have argued that "the notion of the frontier and the boundary are good to think with, as they create meaning in an otherwise unruly universe. And, critically, they provide leads to what there is to protect-what is really at stake. Drawing attention to such boundary processes can thus shed light on the social and organizational dynamics in an organization (Paulsen and Hernes 2003: 13).

\section{Organizational boundaries}

Boundaries-contrary to borders, which can be said to refer mostly to territorial limits-refer to socially constructed elements that a group has established and linked together to separate it from the world around it 
(Fassin 2011: 214). ${ }^{4}$ Hence, boundaries relates to classification, which Bowker and Star (2000) define as "a spatial, temporal, or spatio-temporal segmentation of the world" (ibid. 10, Italics in original). In their seminal book on ethnic groups and boundaries, Barth and his colleagues (1969) illustrated the important role of boundaries by demonstrating how these boundaries remained relevant despite the fact that people changed groups and information crossed ethnic boundaries. Barth argued that boundaries exist because they are socially relevant, and that these boundaries canalize social life. As such, one learns more about a group by focusing on the boundary processes than on the cultural elements emphasized within those boundaries (ibid:15).

Managing who is part of the organization and the quality of their attachment is a key task for formal organizations (Batteau 2001). ${ }^{5}$ The continual process of defining who is inside and who is outside these boundaries can be referred to as "boundary work" (Gieryn 1983).

To understand the implications of boundary processes in formal organizations, the open system perspective can be a useful point of departure. According to Scott and Davis (2007), three perspectives on the nature of organizations have dominated organizational theory in various combinations over time: (1) the rational perspective; (2) the natural perspective; and (3) the open system perspective. The first emphasizes the importance of an organization's formal structures to understand organizational life. The second attacks the first for not taking into consideration how its surrounding environment influences the organization. And the third, the open system perspective, criticizes the previous two for their understanding of organizations as closed systems, rather than as having an interdependent relationship with their surrounding environment (Scott and Davis 2007). Organizations are "open to and dependent on flows of personnel, resources, and information from outside" (ibid. 31). This interdependent relationship with the outside world complicates a formal organization's boundary processes, particularly in terms of the control and coordination of activity. An organization's boundaries need to be "sieves, not shells" (ibid. 152) not only porous enough to allow desirable flows of people, technology, and ideas to cross the organizational boundaries, but also sufficiently impermeable to enable some control and to protect the organization from

\footnotetext{
${ }^{4}$ Sociologists Lamont and Molnár (2002: 168) further make a distinction between symbolic and social boundaries. Symbolic boundaries refer to the conceptual distinctions people use to categorize the world around them, and social boundaries refer to more objectified forms of difference that affect the resources and social opportunities to which people have access. This distinction is a useful reminder that, even if all boundaries are a result of relational processes, some are more institutionalized than others.

5 Batteau focuses on staffing, selling, and bookkeeping as three fundamental instruments in an organization's effort to define who is in and who is out, what role a person has, and what resources are at the organization's disposal.
} 
undesirable elements. Control is further complicated in that the criteria for assessing whether something is harmful or desirable can vary depending on the situation (Scott and Davis 2007). One illustrative case is Garsten's (2003) empirical study which shows how the use of temps means that these individuals can mediate between organizations and be involved in transforming organizational boundaries by playing an active part in both making and breaking them.

The open system perspective focuses on the individual parts that make up a system, the connections between them, and the critical role of information in linking these various parts of the system together. Most important, it does not presuppose that all parts of such a system are necessarily equally connected, which turns the connections into empirical questions. Moreover, it implicitly suggests that there might be situations where external relationships can be more influential than internal ones for employees to conduct their activities. Thus, rather than treating the outside world as something from which an organization needs to protect itself, the outside world is now acknowledged as an indispensable part of how the organization structures its activity. While the critique from the "open system perspective" raises important questions challenging our understanding of organizations, it contributes less in respect to how to answer these questions. In my view, this is a call for anthropology to engage more closely with such matters in the study of organizations. One of the strengths of anthropological studies of organizations is how they demonstrate cultural complexities, and how corporate ideas get challenged by various cultural practices (e.g. Garsten 1994, SalzerMôrling 1998). However, with a few exceptions (e.g. Batteau 2001), there seems to be little reflection within anthropology on what is said to be an organization.

As Paulsen and Hernes (2003) have pointed out, fluidity and complexity do not mean that boundaries are disappearing, but rather that they are being reconfigured in various ways. Anthropology should be particularly suitable to shed light on such processes. Kraakman (2001: 158-59) has noted that, on a legal level, the boundaries of the organization are still clearly set (quoted in Scott and Davis 2007: 388). Yet both Dicken's (2011) definition of transnational companies, which focuses on their ability to control and coordinate activity, and the open system perspective's emphasis on how "external" relationships might be just as important as "internal" ones for a company's operation, challenge the value of an a priori definition of the organization by these legal boundaries. Hence, these legal lines surrounding the organization might very well be a relevant boundary marker for the employees. Yet, when organizations build influential bonds with parties outside these legal lines; who is to say that these parties are not just as important for the employees' definition of the organization they work for? One should look at the various social dimensions used by members of a "community" to set their boundaries, rather than assume the boundaries beforehand by 
defining them according to some presumptions about what is most relevant (Gusfield 1975:31-33 in Van Maanen and Barley 1984: 26). In my view, the fact that a company is receptive to making influential external bonds also invites the following question: is the inside as unproblematic to define as one might conclude from organizational theoretical concepts like "outsourced"? Is there an easily identifiable organizational entity that involves itself in "external relations"? In the case of Supply Inc., a large part of its marketing concept focuses on a global reach, which requires the use of external agents. Yet, despite the existence of external bonds, it is important for Supply Inc. to be recognized as an organizational entity in its own right. The boundary processes involving these external relationships can provide important clues as to what it is important to control and protect to be able to exist as an organizational entity called "Supply Inc." which is separate from these interdependent relationships. The ever-changing processes that help define the boundaries are thus essential to understanding how Supply Inc. functions. As Paulsen and Hernes (2003: 7) advocate, "if boundaries exist and they are decisive, we have to make sense of them in their complexity. It is not helpful to resort to the explanation that they are simply contentious, multiple, ambiguous, and changing."

Earlier, I briefly mentioned Barth's contribution to the study of boundaries. While Barth's perspective is a fundamental contribution towards focusing our attention on empirical investigation of how boundary markers communicate difference between social groups, his focus on difference lacks the analytical vocabulary to address the shared space that is created through the interdependent relationship described above. In my view, the perspective is also less helpful when our aim is to understand how multiple boundary markers can be at play simultaneously, resulting in a situation where people use these markers to draw boundaries in different ways depending on the given situation. How can it, at one level, make sense to include these other parties in our analysis of what this company is, when, at another level, it also makes sense to talk of this transnational company as an entity in its own right? Here other conceptual tools are needed, and I find the concept of "boundary object" useful (Star 1989, Star and Griesemer 1989, Bowker and Star 2000). This is a concept that seeks to understand how an object can remain relevant for multiple users despite the fact that they do not share the same definition of the object. An example of such a "boundary object" in a transnational company can be a computer system where management and workers use the same system, but for different purposes. A key point here is that, as it is difficult for an object to perfectly fulfill the needs of all users simultaneously, such objects will always involve a tension between these different needs. Bowker and Star (2002: 286 -87) refers to this tension as "categorical work." One might also view the transnational company in itself as a boundary object.

The concept is useful because, rather than focusing on boundaries 
as limits between the various parties, it focuses on boundaries in terms of making a "shared space" (Star 2010). As Lamont and Molnár (2002: 187) comment, the concept helps focus attention on what connects and enables coordination in social groups. Yet, it always treats the object like a work in progress requiring significant "categorical work" from the employees involved. Harvey (2012: 122) comments that "boundary object," as suggested by Star, "allows the coexistence of ontological difference and commensurability. Boundaries are thus negotiated but not erased." The boundary markers that come into play through the negotiations between the actors involved will provide important information about their own understanding of this object. 6

In what ways are boundaries constructed and negotiated? How does boundary work toward these external actors take form? When, and in what ways, do boundaries become relevant? To answer these questions, I present a rather complex picture of situations where boundary processes are actualized within Supply Inc. I purposely focus on different levels of the organization, as well as on boundary processes along different dimensions. I endeavour to show how boundaries are negotiated and even manipulated. According to the literature discussed above, managing boundaries is essential for organizations; these boundaries need to be flexible as the definition of who is inside and outside them might depend on the situation and perspective. Hence, it is vital to examine how boundaries are actualized at different levels and in different situations.

\section{Ambiguous organizational boundaries}

The three cases presented in the following section all shed light on different dimensions of boundary work for the employees of Supply Inc. I aim to problematize the criteria for defining who is inside and who outside these boundaries, as well as in what situations it matters to emphasize this difference between insiders and outsiders. In quite different ways, these three examples also touch upon the significance of geographical localization.

The first two examples shed light on the relationship between the two parts that are not formally part of the legal entity Supply Inc., but play an important role in its formation. In the first empirical case, I focus on the relationship with the conglomerate by presenting a situation that occurred when the strategic marketing staff at the headquarters worked

\footnotetext{
6 The term "boundary object" can be criticized for being a slippery concept in that it can refer to everything and nothing, a critique Star (2010) has tried to answer by clarifying what goes into it. I am sympathetic to the critique, yet still find the concept useful because of its specific emphasis on what keeps things going despite differences, e.g., the infrastructure necessary for cooperation and communication to take place. It allows a dimension to the discussion that I find difficult to capture using other concepts.
} 
with the company's visual profile, a job that led to close interaction with the relevant staff at the conglomerate headquarters. The second case focuses on the branch office in Argentina's interaction with one of the external agents they administer-in this particular case, an external agent with which the company has had a relationship for many years.

The third example addresses boundary work within the formal legal entity of Supply Inc. As mentioned earlier, Supply Inc. delivers a range of different products and services to its customers, and this vast offer is divided into four different business streams-all with their separate organizational chain of command, yet ultimately answering to the same senior vice president of global operations (VP). In this empirical case, the message the employees are presented with that these four streams result in the "unity" of a single company is questioned as one stream is asked to compete on the same basis as other firms for a contract for one of the other business streams.

\section{The conglomerate}

All members of the marketing department at the headquarters for Supply Inc. were on their way to a small café located a short walk from the office. The invitation to this excursion came from their boss, the VP of marketing, and the reasons given in the email invitation were that the sun was shining, it was Friday, and, above all, they deserved a treat after finally winning the battle against the conglomerate concerning the graphic profile of the company's business cards.

The atmosphere among the employees was therefore good. The story was that Supply Inc. had recently changed its company name and implemented some organizational changes. Such changes demanded the creation of new business cards, so the marketing department ordered the cards and, at the same time, sent out new guidelines to all Supply Inc. employees. However, the marketing department had to halt its order upon learning that the new guidelines concerning the combination of capital and small letters in a person's title on the business card did not comply with the conglomerate's guidelines.

Initially, the employees involved in the marketing department figured that this was going to be an easy matter to settle because they were sure that, in contrast to the conglomerate's version, their suggestion complied with English grammar rules. ${ }^{7}$ However, the dispute dragged on, and the matter was settled only after the president of Supply Inc.

addressed the issue at an executive board meeting of the conglomerate.

With the dispute settled in their favour, Supply Inc.'s marketing team enjoyed their buns and coffee. While celebrating, the dispute came up as a topic of discussion, and all present agreed that they found it quite

\footnotetext{
${ }^{7}$ English was the official company language.
} 
absurd that a dispute about a small detail (such as the type of capitalization used on a business card) had to be settled at an executive board meeting. They were also convinced that this was not a one-off incident. As a case in point, one of the marketing employees, a graphic designer, shared with her colleagues around the table the fact that a similar discussion was being carried out concerning what colours to use on the marketing materials for Supply Inc. In a meeting she had attended, along with representatives from the conglomerate, about "identity web" (a shared platform where all the companies that were part of the conglomerate could find their graphic profiles), one of the conglomerate representatives rejected one of the chosen colours for Supply Inc. on the grounds that, according to the graphic designer, she "did not like it." The frustration of the employees seated at the table while discussing this incident was palpable. The group seemed to perceive her stated reason as a subjective judgment, and not one related to company guidelines. The graphic designer said that she felt her professional competence had been called into question.

At this point, the VP turned to me and indicated that the conglomerate had a tendency to get too hung up on small details. He commented dryly, "if you want to buy another company, that's no problem; but changing business cards-now, that's impossible!" (my translation).

The VP of marketing's statement reflected a view that central management in Supply Inc. had much more autonomy when it came to making strategic decisions (e.g., whether or not to buy a company), as opposed to other decisions that were decidedly less so (e.g., the capitalization style used on business cards). While this in some ways was an exaggeration to prove a point, he touched upon a key element concerning how the conglomerate was constructed-a structure involving many different sectors, but with some commonalities. As Scott (1998) argues, an important aspect of standardization is who has the authority to set the standards. Those areas where the actors involved make a point of emphasizing their authority hint at what is important for the people involved to protect. I asked the VP of Human Resources (HR) for the conglomerate, whether it was really the case that it was easier to buy a company than change business cards. She laughed and said that yes, this was partly true. HR and visual profile were key elements for the conglomerate to control, relating to reputation and to the possibility of being recognized as a group.

The span in industry affiliation within the conglomerate however, means that the companies had to have a great deal of autonomy in day-today business-related manners. For example, if the staff within Supply Inc. wanted to buy a company to strengthen their own market position within an already existing business area, the competence to assess this strategic move was primarily located within the management structure of Supply 
Inc., as it alone knew both the industry and the market. In regards to Supply Inc.'s relationship with the conglomerate, this explains the managers' impression that it was easier to buy a company than change business cards.

The empirical example presented seems to suggest a relationship that extends to the conglomerate, where the internal processes of Supply Inc. come to a full stop if the conglomerate meddles in certain matters. At the same time, it indicates that defining the boundaries between the two parties is a continual process, wherein the actors implicitly debate the authority to set the standard-yet in a way that makes the Supply Inc. employees emphasize the boundary between the two parties. It is clear that if the analytical goal is to understand Supply Inc. in respect to HR policies, visual profile, and so on, this discussion cannot ignore the wider setting of the conglomerate. This has implications for any discussion of organizational form.

\section{The agents}

After a long bus ride, I arrived at the location of one of the four agents that Supply Inc. uses in various locations as part of their operation in Argentina. The staff at the Supply Inc. office in Argentina had encouraged me on several occasions to visit this particular agent who had been working as their agent for several years. His office was situated in a port visited frequently by customers of Supply Inc. and he was one of two agents in Argentina who had their own warehouses stocked with goods from Supply Inc. that were often sold in their port. Although this agent's office was allowed to have product stock, it did not have access to the computer systems used by Supply Inc. to manage stock at the latter's warehouses (with the exception of limited access to one particular computer program). This restricted and heavily-controlled access to the Supply Inc. computer systems allowed the company to position its agents outside the Supply Inc. boundaries, as IT systems were an important tool used to manage these boundaries (Giskeødegård, 2013). Yet, the agent has quite a liminal position between inside and outside if one considers the long-term relationship between the branch office and the agent office, the agent's contact with Supply Inc. customers on their behalf, and the fact that they did have product stock. As such, a closer look at how the agents and the Argentine staff give meaning to this relationship provides valuable insights into these boundary processes.

Although this office consisted of twelve employees in addition to the manager, the staff in Argentina often referred to it by the name of the current manager, who had assumed responsibility for this office from his dad. Father and son had been running the office together for years, and had a relationship with Supply Inc. that went back twenty years-a relationship which had survived several changes and acquisitions. In fact, throughout the duration of the relationship between this office and the 
Supply Inc. office in Argentina, the latter has undergone at least three different company name changes.

I would not be arriving empty-handed. I was transporting two things on the bus that day: one was a personal gift from the employees at the Argentine office to the manager at this office who had just had a baby daughter; the other was a package of T-shirts and vests with the Supply Inc. logo for all the staff at the agent's office.

Upon my arrival, all twelve employees gathered to greet me. When the manager introduced me, he mentioned that I had brought the Tshirts. The most common comments elicited from people in the room at this news were "finally" and "about time." The staff seemed genuinely happy to receive the clothes. One explained that five years had passed since they had first formulated the idea of wearing clothes with the company logo on them when delivering to Supply Inc. customers. When they initially mentioned this idea to the staff at the Supply Inc. office in Argentina, they had had the impression that this would be possible to arrange.

When I asked the manager to describe their relationship with Supply Inc., his answer was somewhat ambivalent. He was hired simply to do a job for the company. He explained that his company did not introduce itself as Supply Inc. when making deliveries. However, he added that as far as the vessels were concerned, they were Supply Inc. because they arrived with Supply Inc. papers and stated their purpose as delivering Supply Inc. products. He also characterized the staff at the Supply Inc. office in Argentina as being good colleagues. The manager mentioned that he had the employees' private phone numbers and that he felt free to call them if a situation should arise. They always answered the phone, no matter what time of the day or night, although - he added with a twinkle in his eye-not always with a cheery voice.

In this empirical case, boundaries are also on the agenda, as when the agent challenges a given boundary marker by asking Supply Inc. to provide him with Supply Inc. clothes to wear when his staff represent the company in port. The agent is also quite ambivalent in his answer to the question of affiliation, describing a personal bond with the local staff that he does not see as valid for the organization as a whole. In matters relating to Supply Inc. deliveries, one might say that access to Supply Inc.'s technological infrastructure and visual profile separates the two parties as being either inside or outside the company's organizational structure. The importance of the visual profile is demonstrated in how tedious the process was to get t-shirts with the company logo on them to use when delivering products to relevant customers. However, the relationship between the two parties is more personal than one might expect from the organizational labels. In fact, staff members at the office in Argentina have known this agent office longer than their own central management at the company's headquarters. When the same office has 
been the agent in one location for twenty years, and many of the vessels frequently travel to the same port, one might presume that, as far as the vessels are concerned, this agent is the face of Supply Inc. The agent, moreover, knows the company well, understands how the Argentine context affects that type of business, possesses a great deal of knowledge about internal procedures carried out in Supply Inc., and is familiar with relevant people in the organization. As such, the cost of replacing him with another agent would be quite significant. There were several situations where the staff in Argentina felt that the headquarters for Supply Inc. did not understand local conditions (often related to dealing with complex Argentine customs), thereby making the agent and the local branch office "allies" in advocating their case. In other situations, the agents were clearly outside the company core. For example, the new manager at the office made a point of a social visit to each of the agents when she started, which she said also was a way in which she could control the office. However, for Supply Inc. and the agent alike, the relationship between the company and the agent was a formal, impersonal one-a point that sheds light on how boundaries depend on both situation and position.

\section{Products vs. Logistics}

The two cases described so far addressed boundary work towards entities that are not formally part of Supply Inc., yet which are crucial in its formation. As such, the core of the "inside" remains unproblematic, as the examples address situations where these boundaries are expanded to include other actors who would be defined as outside if the legal entity were the point of reference. However, my last example is included precisely to challenge the notion of an unproblematic, unquestionable core. In the last empirical example, all parties involved are formally employees of the legal entity Supply Inc. As such, the empirical case is important because it demonstrates that boundary work, as discussed in this article, is not just relevant when the involved parties belong to different legal entities, but also exists within the same legal entity. Together, these three example open up for a later discussion further on challenging how we think about boundaries in the light of concepts like outsourcing.

This last empirical case involves two different Supply Inc. business streams-that for products and that for logistics. Similar to how the conglomerate sectors its activities based on industry affiliation, Supply Inc. organizes the various types of company activities into different business streams. Supply Inc. mainly advertises these business streams both internally and externally as complementary parts of the same unit and organizational "community." In other words, Supply Inc., with all its parts, is one global organization. There are some situations, however, where this message of unity becomes somewhat ambiguous. 
One such situation occurred when the business stream for products was looking for someone to transport these products around the world. This job did not automatically go to Supply Inc.'s own logistics division; instead, central management asked the latter to provide a tender for the business in the same way as was required of Supply Inc.'s external competitors. This request for a tender came despite the fact that these two business streams ultimately answered to the same VP, Brian, responsible for the overall company value chain/global operations.

As the logistic division was writing this tender, the atmosphere at the Supply Inc. headquarters in Norway grew rather tense. I asked the employee writing the tender, to explain the arguments for this arrangement. She replied that this was just how things were done. However, following the last reorganization that had resulted in the two business streams ultimately answering to Brian, she expressed surprise that he had not intervened to make the divisions focus on the broader picture (i.e. Supply Inc. as a company).

The topic of requesting tenders resurfaced at the branch office in Texas when Brian (the VP in question from Norway) and a central manager from another European office were visiting. This topic was not on the agenda for the meeting, but quickly became one. The local employees who were present seemed eager to convince Brian to reverse the decision to ask for tenders for delivering products, rather than simply using the internal logistics division. The atmosphere at this meeting was unlike any other I had witnessed so far, as it was clear to me that there was considerable tension between the parties. It soon became apparent that Johnny, the American manager of Logistics, and a coworker of his wanted to use this opportunity to demonstrate their own competence so as to try to change the decision to use tenders rather than just automatically turning logistic of products over to their own logistic division. Finally, Johnny even asked Brian directly if he were on board with the decision to turn it into a competition. Brian dodged this question by simply stating that the decision had been made; he then led the discussion in another direction.

In many ways, this situation made the setting of boundary markers debatable. It demonstrates a strategic manipulation of boundary markers by central management, where one of the business streams for a specific purpose was defined as external. Thus, two parallel messages were being communicated simultaneously: one idea of the "global community" Supply Inc., and another of specific tasks separating the organization according to business activity. The seeming lack of connection between these two messages was evident in the tense atmosphere that arose from the decision to call for tenders, since it clearly challenged employees' understanding of the organizational message of common purpose and unity. Understood through the concept of "boundary object," one can read this situation as a tension between the 
particular needs of each division-products wanted the best price, and logistics wanted the business. In this case, "logistics" refers to the "shared" Supply Inc. as it in this situation in an argument in their favour considering that meant products should use their services as they were part of the same team; in the light of this rhetoric of "one" company, it makes sense to think of the "bigger picture" where the costs of hiring someone to perform the logistics would ultimately go back into the company as the cost in the product division would end up as earnings in the logistics division.

\section{Discussion}

Concepts like "outsourced" imply a certain way to think about boundaries, where the inside and outside are two clearly separated entities that can be discussed in relation to each other. Yet, the empirical data here call into question the idea that such an inside "core" exists-or at least, what that core consists of.

In the third empirical case, internal company boundaries are redefined for seemingly financial purposes, in a way that makes the employees question the parallel message of "unity." Besides, the empirical example from the Argentine agent shows that identifying an activity as "outsourced" says nothing about the type of relationship that exists between the parties, nor about the importance of the outside actor to the company involved. This begs the question of what we actually understand about the particularities of organizational life through concepts like "outsourced." Bowker and Star's (2000) use of "boundary object" provides a helpful concept to make sense of the boundary processes involved in such relationships, because it shifts our focus to how these boundary negotiations are part of creating a shared space. It leads to a discussion that takes seriously Barth's advice to look closer at how boundaries are drawn, rather than at where they are, as this gives important insight into what people take care to protect. Yet, the concept stimulates a shift in focus towards the process of creating of a shared space rather than a quest to get to a definitive answer about the difference between these parties (i.e. where the boundary between them is actually drawn).

The empirical cases demonstrate that multiple layers of ambiguous and shifting organizational boundaries are actualized simultaneously, where what is included inside the boundaries (as well as what is excluded from them) depends on the position taken and the boundary marker chosen. Yet, the entity "Supply Inc." never ceases to be a relevant point of reference. In the case of the conglomerate, the empirical example clearly illustrates the power of the conglomerate to influence internal processes within Supply Inc., as the employees had to relate to their input. In terms of organizational boundaries, this situation shows a quite ambivalent boundary process - the conglomerate is simultaneously 
defined as inside (in terms of authority), and outside, through the negotiations of power that put the company boundary on the agenda between the two entities. The relationship between the two legal entities is even more complex due to the intertwined organizational structure presented earlier. There were examples of employees whom did not necessarily relate much to other employees within the same company in their daily work; for example, the VP of HR in Norway performed a substantial amount of his work outside the entity Supply Inc. (taking Supply Inc. as being defined by legal boundaries). Moreover, the conglomerate and Supply Inc. headquarters had offices in the same building (but on different floors). In this building, there was a joint personnel canteen where the staff of the various companies belonging to the conglomerate ate lunch at the same time. Various social activities (e.g. aerobics classes, golf lessons, sailing courses) and recreational and leisure facilities (e.g. company cabins for rent) were also open to all local employees of all the companies belonging to the conglomerate. In many situations, the employees located in the headquarters joined in activities together and, in the process, created a sense of fellowship across these various companies. On the other hand, the employees of Supply Inc. located in Norway, who worked closely with staff from the conglomerate, were also the ones who had the clearest sense of the difference between the two organizational levels. As Barth would comment, difference is always most important when two groups are in close contact. Their work means continually negotiating these boundaries and the difference between them is as a result visible, crucial, and reproduced every day through their work.

All these empirical cases demonstrate that, on one level, it makes sense to draw both emic and etic boundaries around the legal entity Supply Inc. Even though the formal organization "Supply Inc." is viewed as interconnected with its surrounding environment, it is nevertheless recognized as an organization-and remains a relevant point of reference for the employees. Yet, making the boundaries equal to these legal lines would be highly misleading. The three empirical cases presented above all show boundary work involving different dimensions, where the same employees draw lines in different ways depending on the matter at hand. These processes not only expand the outer ends of this legal unit by including alternately the agents or the conglomerate, but also questions the core when one business stream is defined as an entity outside the other business stream, under-communicating their shared platform as parts of Supply Inc. As such, it is helpful to understand these dimensions by viewing them as "categorical work" of the transnational company, where these boundary processes are where the needs of the "shared" and the "particular" are negotiated.

These examples also hint at the importance of physical presence and day-to-day interaction with regard to staff members' perception of who their closest colleagues are. Anthropological studies have always 
emphasized the importance of paying attention to informal interaction and social arenas when creating a community (e.g. Orr 1990). The relationship with the conglomerate is interesting in this respect because, on the one hand, geographical proximity facilitated a sense of affiliation and community in the wider conglomerate through day-to- day interaction and shared activities-including a Christmas and summer party. On the other hand, the fact that many of the employees worked on tasks closely related to the conglomerate's concern also made these Supply Inc. employees acutely aware of the two organizational levels as they interacted through their work. This awareness differed from the situation in the other offices I visited. In Argentina and the office in the United States, the difference between the conglomerate and the Supply Inc. headquarters was not particularly clear. When employees spoke of upcoming activities initiated by one of them, or policies they had to follow, they talked about them as coming from the headquarters, or "Norway," which meant a conflation of the two levels in the regions. Hence, this empirical case shows that the geographical dimension is simultaneously working to create distance and closeness between the two organizational levels. For the company world geographically far from the headquarters, these two levels are largely conflated, as it matters less there who decides what, than it does at the headquarters where the work means constantly negotiating authority to set standards.

In Argentina as well, the geographical dimension is important because the agent and the branch office share an understanding of the intricacies of Argentine customs and legal regulations, the challenges caused to deliveries by the long-stretching geography of the country, and so on. Yet, while the relationship between the people involved is quite personal, employees and agent alike see themselves as two different organizational entities.

Geographical proximity might very well be very important for employees' sense of community, but, as the third empirical example in particular illustrates, there might also be situations where business activity might be more relevant to creating a sense of common purpose and community. The situation could indicate a sense of common purpose along organizational lines, rather than between employees working in the same office, as the logistics division's staff members in both Norway and the US found when they shared the common purpose of trying to overturn this decision.

In all these cases, employees' understanding of their own purpose and task is key to understanding boundary processes. Inclusion and exclusion seem defined by the criteria of how they allow employees to best perform their own job as Supply Inc. employees. In one way, one might say that the shared space of Supply Inc. as a boundary object concerns what Supply Inc. does, while negotiations between the employees representing the various parties largely concerns the 
definition of who does what and in what way. That is, the main concern for employees is their ability to perform their tasks as they see best.

\section{Concluding remarks}

In the theoretical debates above, one talks of the relationship that a formal organization has with the world "outside" itself. I find that the empirical data presented here raise the question of whether this "outside," or even "inside," world is easily identifiable. As such, the empirical examples suggest that there is a need for new analytical concepts if our aim is to understand the particularities of organizational life. Moreover, the situation quite clearly calls for a type of empirically based studies for which anthropology is particularly suited. However, this requires the anthropologist to engage more seriously with the topic of organizational form - to turn the boundaries of the organization into an empirical question. Thinking of the organization through Bowker and Star's (2000) "boundary object" enables a shift in focus towards the effort of creating something shared rather than inside versus outside. The negotiations between the parties can be understood as a result of the tension between the particular needs of each of the individual actors/divisions that continually help produce the shared space.

Supply Inc. never ceases to be a relevant point of reference for employees in these negotiations within a constantly changing landscape, an activity Bowker and Star (2002) refer to as "categorical work." Supply Inc. as a company has a given purpose-to deliver products and services to its customers. The other actors appear as supplementary to this purpose. The criteria for defining actors as inside or outside seem directly related to employees' ability to perform their tasks as they see best. Supply Inc.'s formal organization works as a way to communicate this difference and to state their ground if needed; yet the formal organizational structure does not seem to be the primary way to define the relevant organization. The focus on the task at hand helps explain how it is possible to draw boundaries around the organization at different places, depending on the position taken and the boundary marker chosen.

\section{References}

Batteau, A. 2001. Negations and ambiguities in the cultures of organization. American Anthropologist 102 (4): 726-740.

Bowker, G. and S. Star 2000 [1999]. Sorting things out: classification and its consequences. Cambridge: Massachusetts: MIT Press.

Barth, F. 1969. Introduction. In F. Barth (ed.), Ethnic groups and 
boundaries: the social organization of culture difference. Oslo: Universitetsforlaget.

Dahles, H. and L. Leng 2005. Boundaries and organizations in Asia: an introduction. Asia Pacific Business Review 11 (4): 449-460.

Dicken, P. 2011. Global shift: mapping the changing contours of the world economy. London: Sage.

Garsten, C. and A. Nyqvist (eds.) 2013. Organisational anthropology: doing ethnography in and among complex organisations. London: Pluto Press.

Garsten C. 2003. Colleague, competitor, or client: social boundaries in flexible work arrangements. In Paulsen, N. and T. Hernes (eds.), Managing boundaries in organizations: multiple perspectives. Basingstoke: Palgrave Macmillan.

Gieryn, T. 1983. Boundary-work and the demarcation of science from non-science: strains and interests in professional interests of scientists. American Sociological review 48 (6): 781-795.

Giskeødegård, M.F. 2013. Connecting the dots: an ethnographic study of interaction and community building in a transnational company. Doctoral Thesis at NTNU, pp. 348. Department of Social Anthropology, Norwegian University of Science and Technology (NTNU) ISBN 978-82-471-4839-6

Harvey, P. 2012. Knowledge and experimental practice: a dialogue between anthropology and science and technology studies. In Fardon, R., O. Harris, T.H.J Marchand, C. Shore, V. Strang, R. Wilson and M. Nattall (eds.), The Sage handbook of social anthropology. London: Sage.

Fassin, D. 2011. Policing borders, producing boundaries. The governmentality of immigration in dark times. Annual Review of Anthropology 40: 213-26.

Lamont, M. and V. Molnár 2002. The study of boundaries in the social sciences. Annual Review of Sociology 28: 167-95.

Nardi, B. 2007. Placeless organizations: collaborating for transformation. Mind, Culture, and Activity 14 (1-2): 5-22.

Orr, J. 1990. Sharing knowledge, celebrating identity: war stories and community memory in a service culture. In Middleton, D. and D. Edwards (eds.), Collective remembering. London: Sage.

Paulsen, N. and T. Hernes (eds.) 2003. Managing boundaries in organizations: multiple perspectives. Basingstoke: Palgrave Macmillan.

Salzer-Mørling, M. 1998. Global och local- från Ämhult till Toronto. Bjärred: Academia Adacta AB.

Scott, J. 1998. Seeing like a state: how certain schemes to improve the human condition have failed. New Haven: Yale University Press.

Scott, R. and G. Davis 2007. Organizations and organizing: rational, natural, and open system perspectives. New Jersey: Pearson Education. 
Star, S. 1988. The structure of ill-structured solutions: boundary objects and heterogeneous distributed problem solving. In Huhns, M. and L. Gasser (eds.), Readings in distributed artificial intelligence. Menlo Park, CA: Kaufman.

Star, S. and J. Griesemer 1989. Institutional ecology, "translations," and boundary objects: amateurs and professionals on Berkeley's museum of vertebrate zoology. Social Studies of Science 19: 387-420.

Star, S. 2010. This is not a boundary object: reflections on the origins of a concept. Science Technology Human Values 35: 601-617.

Van Maanen, J. and S. R. Barley 1984. Occupational communities: culture and control in organizations. In Ybema, S., S. D. Yanow and I. Sabelis (eds.), Organizational culture. Volume II Cheltenham: Edward Elgar.

Marte Fanneløb Giskeødegård holds a PhD in Social Anthropology from the Norwegian University of Science and Technology (NTNU). Her work has focused on globalization of work. She is currently working at the research institute Møreforsking in Norway. She may be reached at marte.giskeodegard@moreforsk.no 